\title{
Índice de transparência da vacinação contra a covid-19 no Brasil: Um estudo à luz da realidade empírica das capitais brasileiras
}

\section{COVID-19 vaccination transparency index in Brazil: A study based on the empirical reality of Brazilian capitals}

\author{
Fabiano Maury Raupp \\ Universidade do Estado de Santa Catarina - UDESC - Brasil \\ fabianoraupp@hotmail.com \\ ORCID: https://orcid.org/0000-0001-9533-2574 \\ Ana Rita Silva Sacramento \\ Universidade Federal da Bahia - UFBA - Brasil \\ anasacramento@ufba.br \\ ORCID: https://orcid.org/0000-0001-6739-5711 \\ Renata Cristina Nogueira Santos \\ Instituto Federal do Norte de Minas Gerais - IFNMG e \\ Universidade Federal da Bahia - UFBA - Brasil \\ nogueira.renatacs@gmail.com \\ ORCID: https://orcid.org/0000-0003-0671-1738 \\ José Antonio Gomes de Pinho \\ Universidade Federal da Bahia - UFBA e \\ Fundação Getúlio Vargas - FGV - Brasil \\ jagp@ufba.br \\ ORCID: https://orcid.org/0000-0002-4122-3652
}

\author{
Recebido: 24 Fevereiro 2021 \\ Revisado: 05 Maio 2021 \\ Aceito: 19 Agosto 2021
}

\section{Resumo}

Objetivo: 0 artigo tem por objetivo caracterizar a prática da transparência ativa das capitais brasileiras na vacinação contra a Covid-19, a partir de uma adaptação do Índice de Transparência da Covid-19 elaborado pela Open Knowledge Brasil. Metodologia: 0 estudo é descritivo, realizado por meio de uma pesquisa documental, com abordagem qualitativa. A coleta de dados foi realizada por meio de pesquisa documental, e analisados pela técnica descritiva. Resultados: 0 extrato com maior ocorrência nos levantamentos efetuados foram capitais com baixo nível de transparência. De qualquer forma, dá para perceber que existe uma busca e engajamento por muitos governos de capitais para realizar este valor tão próprio da democracia, visto a evolução de algumas capitais em termos de pontuação geral, nível e posição no ranking. Contribuições: Em termos acadêmicos, como não foram identificadas pesquisas anteriores sobre a mesma temática no âmbito nacional, o estudo objetiva o preenchimento dessa lacuna. Na questão prática, a contribuição de destaque consistiu no desenvolvimento de um modelo específico para avaliar a transparência na vacinação, o Índice de Transparência da Vacinação contra a Covid-19 no Brasil, instrumento que possui relevância social. Palavras-chave: Transparência ativa; vacinação; Covid-19; capitais brasileiras; portais eletrônicos.

\section{Abstract}

Purpose: The article aims to characterize the practice of active transparency in Brazilian capitals in vaccination against Covid-19, based on an adaptation of the Covid-19 Transparency Index prepared by Open Knowledge Brasil. Methodology: The study is descriptive, carried out through documentary research, with a qualitative approach. Data collection was performed through documentary research, and analyzed using the descriptive technique. Results: The extract with the highest occurrence in the surveys carried out was capital with a low level of transparency. Anyway, you can see that there is a search and engagement by many capital governments to realize this very characteristic of democracy, given the evolution of some capitals in terms of overall score, level and position in the ranking. Contributions: In academic terms, as no previous research on the same topic has been identified at the national level, the study aims to fill this gap. On the practical side, the outstanding contribution consisted in the development of a specific model to assess transparency in vaccination, the Vaccination 
Transparency Index against Covid-19 in Brazil, an instrument that has social relevance.

Keywords: Active transparency; vaccination; Covid-19; Brazilian capitals; websites.

\section{Introdução}

A transparência das ações governamentais é um dos componentes básicos de processo de accountability, típico de países democráticos. Com a emergência da pandemia da Covid-19, e mais recentemente com a aprovação pelas agências de vigilância de vacinas para aplicação em caráter emergencial, a transparência governamental tornou-se condição sine qua non para evitar que práticas do tipo desvios, corrupção e clientelismo na aplicação de recursos públicos para o combate dessa pandemia eclodam em países que, como o Brasil, ainda enfrentam problemas estruturais, não obstante serem, grosso modo, considerados democráticos. Sabe-se que a pandemia da Covid-19 não acabou e novos desafios se apresentam constantemente. Cada desafio pode envolver múltiplas áreas, de diferentes conhecimentos, como é o caso do processo de vacinação. Este ambiente de muitas novidades e incertezas, onde a informação tem um papel imprescindível e sua transparência é mais do que urgente, orienta a pergunta de pesquisa: De que forma as capitais brasileiras atendem às exigências de transparências ativa na vacinação contra a Covid-19?

Para tanto, tem-se como objetivo geral caracterizar a prática da transparência ativa das capitais brasileiras na vacinação contra a Covid-19, a partir de uma adaptação do Índice de Transparência da Covid-19 (ITC-19) elaborado pela Open Knowledge Brasil (OKBR), sendo formulados os seguintes objetivos específicos: a) identificar dimensões e critérios passiveis de analisar a transparência ativa na vacinação contra a Covid-19; b) propor um índice para avaliar a transparência da vacinação contra a Covid-19 no Brasil; c) verificar as condições dos portais eletrônicos das capitais para construção da transparência ativa na vacinação contra a Covid-19.

Quanto à justificativa do estudo, do ponto de vista teórico fez-se uma pesquisa na base SPELL Scientific Periodicals Electronic Library (www.spell.org.br), em 29 de janeiro de 2021, utilizando como parâmetro de busca as expressões "transparência", "vacina" e "vacinação", no título do documento, resumo e palavras-chave, sendo identificados trabalhos que abordaram a transparência na pandemia da Covid-19 como um todo (Pinho et al., 2020; Rodrigues et al., 2020; Raupp \& Pinho, 2020; Santos \& Mota, 2020). Tais levantamentos revelam uma lacuna na área de conhecimento que contribui para justificar a realização do trabalho do ponto de vista acadêmico.

Em termos práticos vários motivos levam a considerar esse esforço investigativo como relevante dentre os quais, a necessidade de diagnosticar o uso tecnologia enquanto facilitadora da disponibilização de informações, neste caso os sites oficiais, para informar e justificar as ações empreendidas pelos entes governamentais em prol do processo de vacinação. Soma-se às questões apresentadas a motivação para desenvolver um estudo dentro de uma linha de pesquisa já existente, a partir de novas abordagens e contornos, com vistas na consolidação e/ou aperfeiçoamento de conhecimentos teóricos e práticos já existentes.

\section{Quadro Teórico}

\subsection{Transparência como parte da accountability}

0 estudo tem na transparência a discussão teórica necessária para dar sustentação ao objeto de investigação. A pesquisa considera a transparência como uma dimensão da accountability, cujo conceito, conforme apresentado por Pinho e Sacramento (2009, p. 1364), envolve "responsabilidade (objetiva e subjetiva), controle, transparência, obrigação de prestação de contas, justificativas para as ações que foram ou deixaram de ser empreendidas, premiação e/ou castigo". Tal conceito decorre de um esforço dos autores, após transcorridas aproximadamente duas décadas desde a publicação do trabalho de Campos (1990), para verificar se alterações políticas, sociais e institucionais contribuíram para que a tradução da palavra accountability fosse construída no contexto brasileiro.

A transparência está situada na dimensão da accountability que contempla os elementos da informação e justificação, notadamente a answerability (Schedler, 1999). Isto significa que nas relações entre governo e sociedade, espera-se que a obrigação do primeiro - governo - de prestar contas de suas ações, bem o direito do segundo - sociedade - de exigir informações e justificações estejam institucionalizados, para que a capacidade de enforcement, ou seja, a outra dimensão do modelo concebido por Schedler (1999), a que contempla o poder de agências aplicarem sanções e até perda de mandato ou função àqueles que transgridam os deveres públicos, possa ser exercida.

"Uma instituição que pretenda atingir a excelência em Transparência deve, além de cumprir plenamente os requisitos legais e qualificar suas notas em medidas objetivas, manter uma política que permita aos diferentes atores sociais identificar os esforços institucionais em busca desse conceito" (Vieira, Pegoraro \& Visentini, 2020, p. 51). Portanto, "a transparência não pode ter um fim em si 
mesma, mas deve ser propulsora de transformações institucionais que garantam acessibilidade e atendimento pleno das demandas informacionais da sociedade" (Idem). Transparência significa "o fornecimento de informações suficientes para tornar governos suscetíveis a críticas. Não fornecer nenhuma informação significa simplesmente descumprir, o que tem custos particularmente baixos quando a imprensa e o controle midiático e institucional são fracos ou inexistentes" (Michener, Contreras \& Niskier, 2018, p. 613).

Zuccolotto e Teixeira (2019) apresentam diversas conceituações e classificações atinentes à transparência, dentre as quais nos interessa de forma particular aquela relacionada à iniciativa: transparência ativa e transparência passiva. A transparência ativa "consiste na difusão periódica e sistematizada de informações sobre a gestão estatal. Resulta de ações voluntárias dos gestores públicos ou de obrigações legais impostas aos órgãos do Estado $(2019$, p. 48). Já a transparência passiva "refere-se à obrigação do Estado em conceder, a todos os cidadãos que o requeiram, o acesso tempestivo aos documentos oficiais, salvo aqueles que estiverem legalmente protegidos por motivo de segurança nacional, investigação pública, direito de terceiros etc. (Idem).

\subsection{Transparência no contexto brasileiro: alguns fragmentos}

É conveniente inserir a discussão do tema no contexto sociopolítico e econômico do Brasil, que cria barreiras para o estabelecimento de uma transparência efetiva para conter a prática de desvios de recursos públicos destinados ao combate da Covid-19 no país. Carvalho, por exemplo, entende que "a frágil democracia brasileira precisa de tempo" (Carvalho, 2014, p. 224), acenando como positivas a implantação da Lei da Responsabilidade Fiscal de 2000, a Lei da Transparência de 2009 e a Lei da Ficha Limpa, de 2010. Porém, esse avanço não se deu no que concerne à "igualdade perante à lei, transparência e respeito à coisa pública, sobretudo ao dinheiro do contribuinte" (Idem, p. 245).

Martins (2016) identifica uma "sociedade anômica" que parece ser "moderna e avançada e é de fato uma sociedade atrasada" (Idem, p. 149). A partir desse diagnóstico "parece haver razões de sobra para não prosperar propostas que mexam com essas estruturas tradicionais" (Pinho, 2016, p. 135). 0 Brasil se apresenta como um país de história lenta no sentido de permanência das estruturas tradicionais. Quando mudanças são introduzidas, como a observância da transparência dos atos governamentais e o combate à corrupção, caminhos são buscados no sentido de obstaculizar ou inviabilizar as mesmas de modo a manter o status quo (Martins, 2011).

Convergindo com essas ideias, Pinho enfatiza como "as forças da tradição, da permanência no Brasil ainda são fortes" (Pinho, 2016, p.138), indicando que estaríamos "condenados a mudanças incrementais e lentas". Apesar deste cenário, o autor aponta como avanço a punição de membros das elites, "coisa inimaginável, poucos anos atrás" (Idem, p. 138), nos levando a defender que a conquista da transparência parece se tornar um valor na sociedade brasileira, mesmo que a passos lentos e com resistências. Dado esse estado de coisas, não é surpresa que em condições de pandemia, as estruturas da corrupção, aproveitem a oportunidade, para práticas ilícitas. Ao analisar a reforma do aparato administrativo do Executivo federal no Brasil, Pinho (2016) notou uma série de obstáculos estruturais que podem ser extrapolados para outras áreas do Estado brasileiro. Assim, o que se concretiza em que países mais desenvolvidos, onde existe mais eficiência na administração pública, não ocorre em "países de extensa burocracia, com acentuado legalismo e formalismo e forte autoridade hierárquica" (Motta, 2013, p. 86).

Existe uma intrincada engrenagem que parece feita para funcionar para as classes privilegiadas que tem acesso ao aparato do Estado por caminhos não republicanos. 0 formalismo, nas palavras de um dos principais tradutores deste conceito para o Brasil, Guerreiro Ramos, se dá em sociedades onde "coexistem o antigo e o moderno, o atrasado e o avançado" (Ramos, 1983, p. 251). Na sociedade brasileira "só teatralmente o Estado é moderno e, às vezes, nem assim" (Martins, 2016, p. 150). Em outras palavras, monta-se um teatro para parecer moderno, mas, no fundo, o que manda são as estruturas conservadoras. Mesmo quando nos anos debaixo da égide de partidos progressistas, onde havia uma expectativa de um giro de 180 graus na estrutura política do País, as bases conservadoras e as práticas nefastas do patrimonialismo e do fisiologismo foram mantidas. "As forças da tradição, da permanência no Brasil ainda são fortes" (Pinho, 2016, p. 38).

Convergentes com os autores anteriormente citados, Sacramento e Pinho (2016) admitem que desde a redemocratização avanços institucionais foram formalizados no Brasil no sentido de tornar as ações públicas mais transparentes. Portanto, não é por falta de normativos que o fenômeno enfrenta dificuldades para se estabelecer objetivamente ou subjetivamente como socialmente valoroso no país, tanto no que tange às questões de natureza financeira e orçamentária, como nas que se relacionam com matérias mais profundas da democracia Na linha do tempo construída por esses autores para evidenciar a trajetória da answerability no país constam a criação dos sistemas de informações e do Portal da Transparência, bem como as diversas Leis já editadas que favorecem, direta ou 
indiretamente, esse elemento da accountability.

A prática dos agentes políticos investigada em vários estudos indica que tais instrumentos, embora necessários, ainda são insuficientes para que a transparência aqui seja considerada como de excelência, pois "nem a legitimidade simbólica, nem o monitoramento, nem as preocupações competitivas resultam em compromissos com a transparência" (Michener, Contreras \& Niskier, 2018, p. 613). Aduzem esses autores que "políticos estaduais e municipais majoritariamente valorizam a opacidade em detrimento da transparência" (Idem).

Percebe-se nesta trajetória como a construção da democracia e seus componentes, accountability e, em particular, a transparência, tem sido uma luta árdua no Brasil, ostentando dois períodos ditatoriais na sua história recente (1937/45 e 1964/85). A partir de 1985 a democracia tem se instalando apesar dessas travas estruturais apontadas acima. No caso aqui em tela, não se pode deixar de pontuar que o combate à Covid-19, tem gerado um conflito persistente entre o governo federal e os governos subnacionais desde o início da pandemia, ocasionando não apenas ruídos como também falta de unidade nas decisões e confiança entre as partes envolvidas. Assim, é nesse ambiente turvo que também deve ser analisada a presente questão.

\subsection{Estudos nacionais sobre a transparência em tempos de pandemia}

Com a intenção de buscar uma aproximação ao objeto empírico, será aqui discorrido de forma sintética sobre o estudos correlatos. 0 Quadro 1 apresenta alguns dos estudos identificados.

\section{Quadro 1 - Estudos correlatos}

\begin{tabular}{|c|c|c|c|}
\hline Autores & Periódico & Objetivo & Principais Resultados \\
\hline $\begin{array}{l}\text { Pinho et al. } \\
(2020)\end{array}$ & $\begin{array}{l}\text { Revista da } \\
\text { CGU }\end{array}$ & $\begin{array}{l}\text { Avaliar a construção da } \\
\text { transparência das informações } \\
\text { sobre contratações emergenciais } \\
\text { para o combate da Covid-19 pelos } \\
\text { municípios-capitais do Brasil e sua } \\
\text { relação com o avanço da pandemia } \\
\text { em seus contextos locais. }\end{array}$ & $\begin{array}{l}\text { Os indicadores de transparência apresentaram } \\
\text { melhora significativa ao longo dos três } \\
\text { levantamentos considerados. O avanço no } \\
\text { cumprimento de uma dimensão não tinha } \\
\text { relação com as outras dimensões, exceto controle } \\
\text { social e formato, e entre controle social e } \\
\text { legislação. }\end{array}$ \\
\hline $\begin{array}{l}\text { Raupp e } \\
\text { Pinho } \\
(2020)\end{array}$ & $\begin{array}{l}\text { Gestão e } \\
\text { Sociedade }\end{array}$ & $\begin{array}{l}\text { Analisar a construção da } \\
\text { transparência sobre a Covid-19 } \\
\text { pelos estados brasileiros. }\end{array}$ & $\begin{array}{l}\text { Os estados ainda devem evoluir em } \\
\text { transparência das informações. Depois de um } \\
\text { mês de avaliações semanais, a taxa inicial nas } \\
\text { categorias opaco, baixo e médio, que era de 90\%, } \\
\text { passou para } 39 \% \text { nesta última avaliação, além de } \\
\text { nenhum estado se encontrar na faixa opaco e } \\
\text { somente um estar no nível baixo. }\end{array}$ \\
\hline $\begin{array}{l}\text { Rodrigues } \\
\text { et al. } \\
(2020)\end{array}$ & $\begin{array}{l}\text { Revista do } \\
\text { Serviço } \\
\text { Público }\end{array}$ & $\begin{array}{l}\text { Compreender de que forma as } \\
\text { informações sobre a pandemia do } \\
\text { novo coronavírus estão sendo } \\
\text { disponibilizadas pelos municípios } \\
\text { brasileiros. }\end{array}$ & $\begin{array}{l}\text { Foram observados problemas relacionados à } \\
\text { qualidade das informações disponibilizadas e um } \\
\text { nível muito baixo de resposta de pedidos de } \\
\text { acesso à informação. Gastos e receitas no } \\
\text { combate ao Covid-19 são disponibilizados por } \\
\text { boa parte dos municípios, além de um alto índice } \\
\text { de uso das redes sociais para divulgar } \\
\text { informações. }\end{array}$ \\
\hline $\begin{array}{l}\text { Santos e } \\
\text { Mota } \\
(2020)\end{array}$ & $\begin{array}{l}\text { Gestão e } \\
\text { Sociedade }\end{array}$ & $\begin{array}{l}\text { Promover reflexões sobre questões } \\
\text { já evidentes em torno de como a } \\
\text { transparência governamental, na } \\
\text { atual conjuntura, tem se } \\
\text { desenvolvido. }\end{array}$ & $\begin{array}{l}\text { O atual cenário se torna desafiador para a } \\
\text { comunidade acadêmica especializada no tema. } \\
\text { Há perguntas provocativas que necessitam de } \\
\text { atenção dos pesquisadores, para que se avance } \\
\text { no entendimento desse tipo de fenômeno. }\end{array}$ \\
\hline
\end{tabular}

Fonte: Dados da pesquisa (2021)

A necessidade que os entes governamentais têm de evoluir em relação à transparência sobre a pandemia da Covid-19, de questões sanitárias às contratações emergenciais, é um ponto comum nesses estudos. Por outro lado, tem-se a noção de que se trata de um cenário cuja magnitude e implicações afetaram praticamente toda a população, e mesmo que os governos tenham se mobilizado a darem respostas em tempo célere à sociedade (Raupp \& Pinho, 2020), não havia um gabinete digital específico estruturado para tais emergências, mesmo já existindo uma infraestrutura de transparência (Pinho et al., 2020).

A necessidade de aperfeiçoamento diz respeito tanto à transparência ativa como à passiva. 
Baixas taxas de resposta à solicitações demonstram a qualidade insuficiente de transparência passiva, embora a qualidade das informações disponíveis na transparência ativa também seja baixa (Rodrigues et al., 2020). 0 fato é que pouco se sabe sobre transparência nos momentos em que os governos lidam com crises e incertezas, com é o caso da pandemia causada pela Covid-19 (Santos \& Mota, 2020), constatação que agrega valor ao estudo em tela.

\section{Trajetória Metodológica}

0 estudo empreendido para caracterizar a transparência ativa das capitais brasileiras na vacinação contra a Covid-19 é descritivo, realizado por meio de pesquisa documental, com abordagem predominantemente qualitativa. 0 objeto de investigação contemplou os portais eletrônicos das capitais brasileiras e do Distrito Federal, de forma particular as seções dedicadas à abordar informações sobre o processo de vacinação. As etapas da pesquisa estão sintetizadas na Figura 1.

\section{Figura 1 - Etapas da pesquisa}

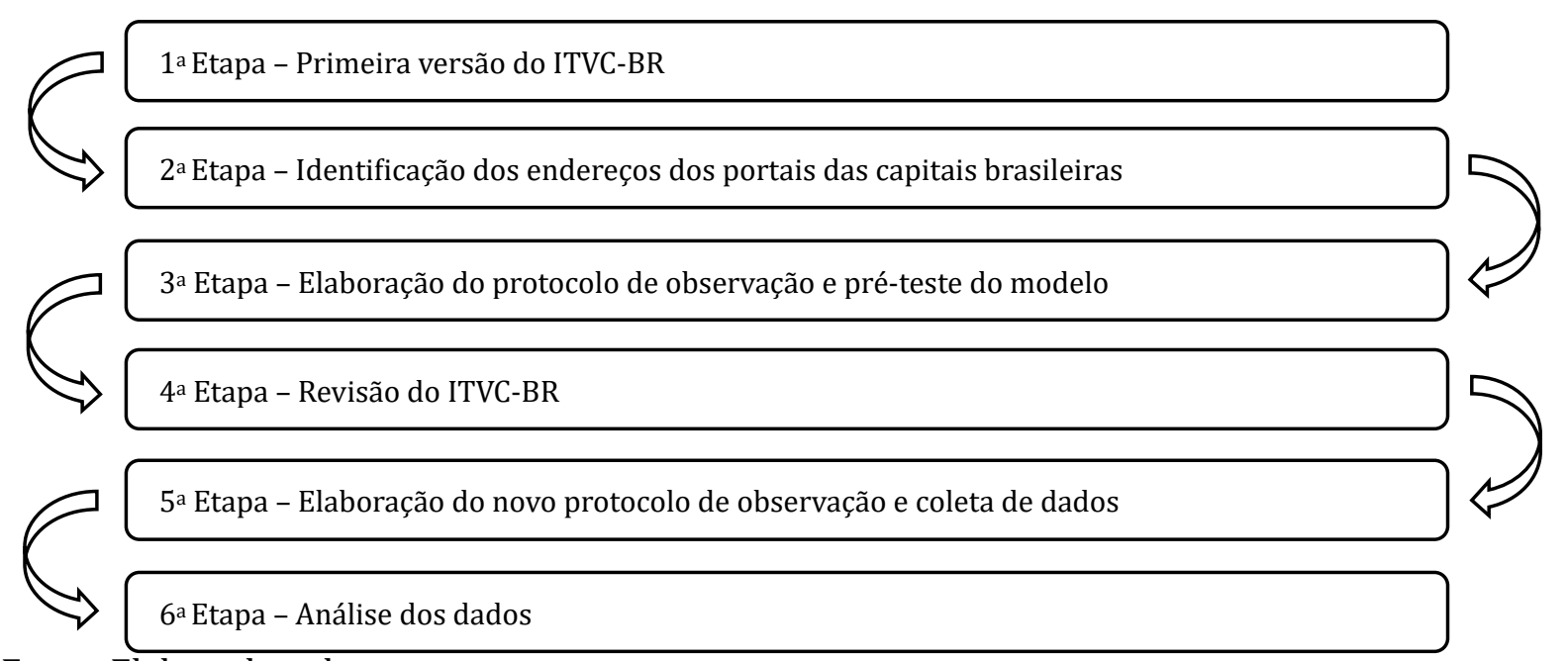

Fonte: Elaborado pelos autores

Estruturou-se a primeira versão do modelo de análise a partir de uma adaptação do Índice de Transparência da Covid-19 (ITC-19) elaborado pela Open Knowledge Brasil (OKBR), conforme demonstrado no Quadro 2. A opção pelo ITC-19 deve-se ao fato de o Índice ter se consolidado como um mecanismo de abertura de dados sobre o novo coronavírus. "Ao servir como norte e estímulo para gestores públicos, o ITC-19 impulsionou consideravelmente a transparência de informações sobre a pandemia" (OKBR, 2020, p. 2). "A OKBR, também conhecida como Rede pelo Conhecimento Livre, é uma organização da sociedade civil sem fins lucrativos e apartidária que atua no país desde 2013" (OKBR, 2020, p. 21).

\section{Quadro 2 - Modelo de Análise (primeira versão)}

\begin{tabular}{|c|c|c|c|}
\hline Dimensão & Critério & Descrição & Pontuação \\
\hline \multirow{3}{*}{ Conteúdo } & População alvo & Quantidade de vacinados por população alvo & $\begin{array}{l}0=\text { não apresenta; } \\
1 \text { = apresenta. }\end{array}$ \\
\hline & Doses disponíveis & $\begin{array}{l}\text { Quantidade de doses que o estado/município } \\
\text { dispõe }\end{array}$ & $\begin{array}{l}0 \text { = não apresenta; } \\
1 \text { = apresenta. }\end{array}$ \\
\hline & Doses aplicadas & Quantidade de doses aplicadas & $\begin{array}{l}0=\text { não apresenta; } \\
1 \text { = apresenta. }\end{array}$ \\
\hline \multirow{3}{*}{ Granularidade } & Microdado & $\begin{array}{l}\text { Quantidade de doses de vacinas aplicadas por } \\
\text { primeira e segunda doses ou por tipo de vacina }\end{array}$ & $\begin{array}{l}0=\text { não apresenta; } \\
1=\text { apresenta. }\end{array}$ \\
\hline & Localização & $\begin{array}{l}\text { Nível de agregação geográfica das doses aplicadas } \\
\text { (por bairro, por estabelecimento de saúde etc.) }\end{array}$ & $\begin{array}{l}0=\text { não apresenta; } \\
1=\text { apresenta. }\end{array}$ \\
\hline & Visualização & Painel para consulta do público em geral & $\begin{array}{l}0 \text { = não apresenta; } \\
1 \text { = apresenta. }\end{array}$ \\
\hline
\end{tabular}




\begin{tabular}{|l|l|l|l|}
\cline { 2 - 4 } Formato & Formato aberto & $\begin{array}{l}\text { Dados estruturados em ao menos uma planilha em } \\
\text { formato editável, de preferência aberto (CSV, ODS) }\end{array}$ & $\begin{array}{l}0=\text { não apresenta; } \\
1=\text { apresenta. }\end{array}$ \\
\cline { 2 - 4 } & Série histórica & $\begin{array}{l}\text { Base única e atualizada com o histórico completo, } \\
\text { desde o início da aplicação }\end{array}$ & $\begin{array}{l}0=\text { não apresenta; } \\
1=\text { apresenta. }\end{array}$ \\
\hline
\end{tabular}

Fonte: adaptado de OKBR (2020, p.17-21)

No processo de adaptação alguns critérios foram criados (população alvo, doses disponíveis e doses aplicadas) para que fosse desenvolvida uma identidade com o fenômeno de investigação, outros critérios foram adaptados (microdado, localização, visualização, formato aberto e série histórica) do índice já existente, sendo gerada a primeira versão do Índice de Transparência da Vacinação contra a Covid-19 no Brasil (ITVC-BR). Quanto às dimensões, o "Conteúdo" diz respeito à "parâmetros que podem auxiliar na produção de análises mais aprofundadas" sobre a vacinação contra a Covid-19", e cada critério recebe Peso 1 na composição do Índice (OKBR, 2020, p. 6). A "Granularidade" "é a dimensão que avalia o detalhamento dos dados divulgados pelas autoridades, fornecendo uma camada extra de informação", e cada critério recebe Peso 3 (OKBR, 2020, p. 14). Já no "Formato" avalia-se "de que maneira os dados foram disponibilizados. A forma de acessar, ler e compartilhar os dados é um determinante do potencial de análise dos mesmos", e cada critério recebe Peso 5 (OKBR, 2020, p. 15). O ITVC-BR, assim como o ITC-19 (OKBR, 2020), é representado em uma escala de 0 a 100, em que 0 é atribuído ao ente menos transparente, e 100 ao mais transparente. Os níveis de transparência foram definidos a partir de intervalos de pontuação, sendo os seguintes: opaco (0 - 19); baixo (20 - 39); médio (40 - 59); bom (60 - 79); alto (80 - 100).

Na segunda etapa da pesquisa foram localizados, por meio de visitas ao site Google, os endereços eletrônicos dos portais mantidos pelas capitais. Para visitar os portais foi elaborado na terceira etapa o protocolo de observação, tendo por base a versão inicial do modelo, e realizado o pré-teste com os portais nos dias 27 e 28 de janeiro de 2021. Nesta etapa foram identificados ajustes necessários ao modelo de análise, chegando-se a uma nova versão do modelo de análise e do próprio ITVC-BR, conforme Quadro 3, que correspondeu a quarta etapa da pesquisa.

\section{Quadro 3 - Modelo de Análise (segunda versão)}

\begin{tabular}{|c|c|c|c|}
\hline Dimensão & Critério & Descrição & Pontuação \\
\hline \multirow{6}{*}{ Conteúdo } & Doses disponíveis & $\begin{array}{l}\text { Quantidade de doses que o estado/ } \\
\text { município dispõe }\end{array}$ & $\begin{array}{l}0=\text { não apresenta; } \\
1 \text { = apresenta }\end{array}$ \\
\hline & $\begin{array}{l}\text { Idade ou Faixa } \\
\text { Etária }\end{array}$ & $\begin{array}{l}\text { Doses aplicadas por idade ou faixa } \\
\text { etária }\end{array}$ & $\begin{array}{l}0 \text { = não apresenta; } \\
0,5 \text { = apresenta uma média geral; } \\
1 \text { = apresenta idade ou faixa etária. }\end{array}$ \\
\hline & Sexo & Doses aplicadas por sexo & $\begin{array}{l}0 \text { = não apresenta; } \\
0,5 \text { = apresenta uma média geral; } \\
1 \text { = apresenta idade ou faixa etária. }\end{array}$ \\
\hline & População alvo & Doses aplicadas por população alvo & $\begin{array}{l}0 \text { = não apresenta; } \\
0,5 \text { = apresenta uma média geral; } \\
1 \text { = apresenta. }\end{array}$ \\
\hline & Tipo de dose & $\begin{array}{l}\text { Doses aplicadas por primeira e } \\
\text { segunda doses }\end{array}$ & $\begin{array}{l}0=\text { não apresenta; } \\
1 \text { = apresenta }\end{array}$ \\
\hline & Tipo de vacina & Doses aplicadas por tipo de vacina & $\begin{array}{l}0=\text { não apresenta; } \\
1=\text { apresenta }\end{array}$ \\
\hline \multirow{3}{*}{$\begin{array}{l}\text { Granulari } \\
\text { dade }\end{array}$} & Microdado & Cada caso é um registro & $\begin{array}{l}0 \text { = não apresenta; } \\
0,5 \text { = apresenta de um grupo de casos; } \\
1 \text { = apresenta. }\end{array}$ \\
\hline & Localização & $\begin{array}{l}\text { Nível de agregação geográfica das } \\
\text { doses aplicadas (por bairro, por } \\
\text { estabelecimento de saúde etc.) }\end{array}$ & $\begin{array}{l}0=\text { não apresenta; } \\
1 \text { = apresenta }\end{array}$ \\
\hline & Visualização & $\begin{array}{l}\text { Painel para consulta do público em } \\
\text { geral }\end{array}$ & $\begin{array}{l}0 \text { = não apresenta; } \\
0,5 \text { = apresenta boletim e/ou notícias; } \\
1 \text { = apresenta painel. }\end{array}$ \\
\hline
\end{tabular}


Raupp, Sacramento, Santos \& Pinho, Teoria e Prática em Administração, v. 11, edição especial em saúde

\begin{tabular}{|c|l|l|l|}
\cline { 2 - 4 } Formato & Formato aberto & $\begin{array}{l}\text { Dados estruturados em ao menos } \\
\text { uma planilha em formato editável, de } \\
\text { preferência aberto (CSV, ODS) }\end{array}$ & $\begin{array}{l}0=\text { não apresenta; } \\
1=\text { apresenta. }\end{array}$ \\
\cline { 2 - 4 } & Série histórica & $\begin{array}{l}\text { Base única e atualizada com o } \\
\text { histórico completo, desde o início da } \\
\text { aplicação }\end{array}$ & $\begin{array}{l}0=\text { não apresenta; } \\
1=\text { apresenta. }\end{array}$ \\
\hline
\end{tabular}

Fonte: adaptado de OKBR (2020, p.17-21)

- Modificações na dimensão Conteúdo: observou-se que no momento do pré-teste não havia sido iniciada a segunda dose de vacinação em nenhuma capital. Foi verificado que algumas capitais informaram a quantidade de doses disponíveis por tipo de vacina/fabricante, porém não especificaram quantas doses de cada tipo foram aplicadas, sendo elas: Belo Horizonte, Brasília, Florianópolis, Macapá, Natal, Porto Alegre, Porto Velho, Recife, Rio de Janeiro, Salvador, São Paulo, Teresina e Vitória. Segundo o Plano Nacional de Operacionalização da Vacinação contra a Covid-19 (BRASIL, 2020), será colocado à disposição do público em geral os dados que dizem respeito ao número de doses aplicadas, por estado e município, em um dado período de tempo, por gênero, por faixa etária e por tipo de vacina. Estes critérios foram adicionados ao modelo, sendo que alguns deles já constam no Índice da OKBR. Ressalta-se que o nome da vacina/fabricante aplicada é uma informação a ser prestada ao público de maneira não individualizada, respeitando a privacidade e confidencialidade das informações pessoais dos vacinados, embora seja uma informação adicionada no registro individualizado da dose aplicada, disponível para consulta por profissionais da saúde credenciados no Sistema de Informações do Programa Nacional de Imunizações, para fins de controle de estoque, evitar duplicidade de vacinação e para identificação Evento Adverso Pós-Vacinação (EAPV) que possa ocorrer após a aplicação das doses.

- Modificações na dimensão Granularidade: o critério Microdado foi modificado para avaliar a divulgação anonimizada de dados relativos a cada caso, separadamente, possibilitando a construção de um panorama mais preciso sobre o avanço do novo coronavírus no país. As bases de Microdados devem observar boa parte dos critérios exigidos na dimensão Conteúdo (OKBR, 2020).

- Modificações na dimensão Formato: em relação ao critério Visualização, cuja descrição prevê um "Painel para consulta do público em geral", foi observado que as informações em relação à vacinação são prestadas por meio das seguintes formas: a) painel: página específica direcionada pela página principal da capital com informações gerais do coronavírus e algumas informações sobre a vacina, em alguns casos denominada de Vacinômetro; b) boletins epidemiológicos; e c) notícias. O Vacinômetro, por exemplo, foi identificado em Florianópolis, João Pessoa, Macapá, Palmas, Porto Alegre, Recife e Salvador.

A quinta etapa consistiu em elaborar um novo protocolo de observação a partir da segunda versão do modelo de análise, bem como promover a coleta de dados nos portais. As visitas dirigidas ocorreram em 30-01-2021, 06-02-2021, 13-02-2021 e 20-02-2021. Os endereços eletrônicos dos portais representaram a porta de acesso as informações disponibilizadas pelas capitais sobre 0 processo de vacinação. Não foi observado um padrão na forma de divulgar as informações, sendo as informações identificadas por meio de pesquisa documental em notícias, painéis e boletins epidemiológicos. 0 material coletado foi analisado a partir da análise descritiva.

\section{Resultados Empíricos}

\subsection{Primeiro levantamento}

Já no primeiro levantamento, feito em 30 de janeiro de 2021, foram observados avanços em relação ao pré-teste. A Tabela 1 apresenta os dados de pontuação, nível e posição das capitais obtidos no primeiro levantamento.

Tabela 1 - Pontuação, nível e posição das capitais no primeiro levantamento

\begin{tabular}{l|c|c|c}
\hline \multicolumn{1}{c|}{ Capital } & Pontuação & Nível & Posição \\
\hline João Pessoa & 85 & Alto & 1 \\
\hline Porto Velho & 81 & Alto & 2 \\
\hline
\end{tabular}




\begin{tabular}{|c|c|c|c|}
\hline Macapá & 74 & Bom & 3 \\
\hline Recife & 59 & Médio & 4 \\
\hline Manaus & 56 & Médio & 5 \\
\hline Porto Alegre & 56 & Médio & 5 \\
\hline Salvador & 56 & Médio & 5 \\
\hline Florianópolis & 44 & Médio & 6 \\
\hline Brasília & 39 & Baixo & 7 \\
\hline Rio de Janeiro & 37 & Baixo & 8 \\
\hline Belo Horizonte & 26 & Baixo & 9 \\
\hline Palmas & 26 & Baixo & 9 \\
\hline Cuiabá & 24 & Baixo & 10 \\
\hline Curitiba & 24 & Baixo & 10 \\
\hline Goiânia & 24 & Baixo & 10 \\
\hline São Luís & 24 & Baixo & 10 \\
\hline Aracajú & 22 & Baixo & 11 \\
\hline Belém & 20 & Baixo & 12 \\
\hline Campo Grande & 20 & Baixo & 12 \\
\hline Natal & 20 & Baixo & 12 \\
\hline Vitória & 19 & Opaco & 13 \\
\hline Fortaleza & 17 & Opaco & 14 \\
\hline Maceió & 17 & Opaco & 14 \\
\hline Rio Branco & 17 & Opaco & 14 \\
\hline São Paulo & 17 & Opaco & 14 \\
\hline Boa Vista & 13 & Opaco & 15 \\
\hline Teresina & 13 & Opaco & 15 \\
\hline
\end{tabular}

Fonte: Dados da pesquisa (2021)

No pré-teste, realizado nos dias 27 e 28 de janeiro de 2021, foi identificado que apenas 7 capitais disponibilizaram informações por meio do Vacinômetro: Florianópolis, João Pessoa, Macapá, Palmas, Porto Alegre, Recife e Salvador. Na primeira coleta, em 30 de janeiro, passados apenas 3 dias, este número aumentou para 10 capitais, com o acréscimo de Cuiabá, Manaus e Porto Velho. Este dado reforça a velocidade com que as tecnologias, neste caso os portais, podem ser modificados e aperfeiçoados, em um curtíssimo espaço de tempo, assim como o levantamento de dados, seu tratamento e publicação, ou seja, a gestão. Neste intervalo também ocorreram modificações particulares, como foi o caso de Manaus. A capital divulgava, conforme observado no pré-teste, lista com nome dos vacinados e CPF, mas na primeira coleta a lista havia sido retirada do site, sendo identificada a utilização do Vacinômetro sem a individualização dos vacinados.

As capitais que não utilizam o Vacinômetro divulgaram informações sobre a vacinação em notícias, painéis, relatórios e boletins epidemiológicos. Buscou-se analisar todas estas ferramentas de modo concomitante. Nos sites das capitais São Luís e Teresina, por exemplo, não foram encontrados boletins epidemiológicos para complementar a busca. Buscou-se nos sites de todas as capitais, mesmo aquelas que usam o Vacinômetro, notícias como forma de complementar os dados levantados. Verificou-se que os Vacinômetros, de modo geral, não trouxeram, no primeiro levantamento, todas as informações constantes no modelo de análise. Destaca-se que o Município de São Paulo ainda não conta com o Vacinômetro, apesar de ser uma capital que avança na vacinação em doses aplicadas e 
doses disponíveis, e algumas notícias do site direcionavam para o Vacinômetro do governo do Estado de São Paulo.

Muitas notícias divulgadas nos portais são escritas com verbos no futuro, relacionadas a expectativas de recebimento de doses, de aplicação de vacinas e de atendimento ao público prioritário. Trazem, também, depoimentos de vacinados, fotos dos prefeitos nos locais de vacinação, questões que pouco contribuem para o avanço na construção da transparência sobre a vacinação. Poucas notícias trazem dados quantificados em relação aos indicadores das dimensões do modelo de análise. Nos Municípios de Florianópolis, Salvador e São Luís não foi possível identificar o número total de doses disponíveis.

Os critérios mais divulgados neste primeiro levantamento foram: doses disponíveis, população alvo, tipo de dose e visualização. Os critérios menos divulgados foram: formato aberto, idade, microdado e sexo. Ressalta-se que idade e sexo estão entre os itens definidos pelo Plano Nacional de Vacinação (BRASIL, 2020) como aqueles que devem ser colocados à disposição do público em geral, por isto chama a atenção a sua baixa ocorrência.

\subsection{Segundo levantamento}

Observou-se no segundo levantamento, realizado em 06 de fevereiro de 2021, que outras capitais aderiram ao Vacinômetro: Aracajú, Belém, Fortaleza, Teresina, Vitória. No total, até a data da coleta, 15 capitais têm feito uso desta ferramenta. A Tabela 2 apresenta os dados de pontuação, nível e posição das capitais obtidos no segundo levantamento.

Tabela 2 - Pontuação, nível e posição das capitais no segundo levantamento

\begin{tabular}{|c|c|c|c|}
\hline Capital & Pontuação & Nível & Posição \\
\hline Porto Velho & 96 & Alto & 1 \\
\hline João Pessoa & 85 & Alto & 2 \\
\hline Macapá & 67 & Bom & 3 \\
\hline Porto Alegre & 59 & Médio & 4 \\
\hline Recife & 57 & Médio & 5 \\
\hline Manaus & 56 & Médio & 6 \\
\hline Salvador & 52 & Médio & 7 \\
\hline Fortaleza & 50 & Médio & 8 \\
\hline Aracajú & 46 & Médio & 9 \\
\hline Brasília & 46 & Médio & 9 \\
\hline Florianópolis & 44 & Médio & 10 \\
\hline Rio de Janeiro & 35 & Baixo & 11 \\
\hline Belo Horizonte & 33 & Baixo & 12 \\
\hline Palmas & 33 & Baixo & 12 \\
\hline Teresina & 33 & Baixo & 12 \\
\hline Natal & 30 & Baixo & 13 \\
\hline Belém & 28 & Baixo & 14 \\
\hline Vitória & 28 & Baixo & 14 \\
\hline Boa Vista & 26 & Baixo & 15 \\
\hline Campo Grande & 22 & Baixo & 16 \\
\hline Cuiabá & 22 & Baixo & 16 \\
\hline Curitiba & 20 & Baixo & 17 \\
\hline
\end{tabular}


Raupp, Sacramento, Santos \& Pinho, Teoria e Prática em Administração, v. 11, edição especial em saúde

\begin{tabular}{l|c|c|c}
\hline Maceió & 19 & Opaco & 18 \\
\hline Rio Branco & 19 & Opaco & 18 \\
\hline São Luís & 19 & Opaco & 18 \\
\hline Goiânia & 17 & Opaco & 19 \\
\hline São Paulo & 9 & Opaco & 20 \\
\hline
\end{tabular}

Fonte: Dados da pesquisa (2021)

Belém aderiu ao Vacinômetro apenas com dados sobre o número de doses disponíveis e aplicadas aos profissionais de saúde e para idosos albergados. No entanto, pelo portal das notícias dessa capital - Belém - verificou-se que foi iniciada a vacinação da população indígena. 0 portal de notícias traz histórias e depoimentos de idosos vacinados e locais de vacinação, mas não apresenta outros dados conforme o modelo de análise, o que fez com que a capital permanecesse no nível de transparência baixo. Assim como Belém, outras capitais que utilizam o Vacinômetro e obtiveram nível de transparência baixo: Cuiabá, Palmas, Teresina e Vitória. Isto demonstra a subutilização deste painel para consulta do público em geral sobre o processo de vacinação.

Comparativamente ao primeiro levantamento, o Relatório de Vacinação de Brasília exibiu menos dados. A justificativa apresentada informa que "devido a maioria das fichas serem preenchidas manualmente, por inconsistência do sistema SIPNI, não foi possível dividir os dados por região de saúde." Foram encontradas mais informações em "Notícias" do que no próprio Relatório de Vacinação. A veiculação de notícias sobre a vacinação foi reduzida entre o primeiro e segundo levantamento. Macapá, por exemplo, não tem mais informações sobre a vacinação em "Notícias" desde o dia 29 de janeiro, tendo utilizado apenas o Vacinômetro como instrumento de transparência. Maceió tem apenas uma notícia sobre a vacinação no dia 01 de fevereiro e ainda não aderiu ao Vacinômetro. A última versão da "Relação de vacinação" da capital Rio Branco, que contempla nome do vacinado, grupo prioritário, unidade de saúde e data de aplicação da primeira dose, foi divulgada em 29 de janeiro, sem atualização até o segundo levantamento. Na página de "Notícias" de São Paulo há informações de orientações sobre a vacinação, locais de vacinação, documentos necessários, mas não foram encontrados dados sobre a maioria dos critérios do modelo de análise, o que chama atenção em razão do porte desta capital. Os critérios mais divulgados no segundo levantamento foram: doses disponíveis, população alvo e visualização. Os critérios menos divulgados foram: formato aberto, microdado e sexo.

\subsection{Terceiro levantamento}

No terceiro levantamento, realizado em 13 de fevereiro de 2021, foi observado que duas novas capitais aderiram ao Vacinômetro: Curitiba e Brasília. Os dados de pontuação, nível e posição alcançados no terceiro levantamento são apresentados por meio da Tabela 3.

Tabela 3 - Pontuação, nível e posição das capitais no terceiro levantamento

\begin{tabular}{l|c|c|c}
\hline \multicolumn{1}{c|}{ Capital } & Pontuação & Nível & Posição \\
\hline Porto Velho & 96 & Alto & 1 \\
\hline João Pessoa & 87 & Alto & 2 \\
\hline Macapá & 67 & Bom & 3 \\
\hline Rio Branco & 67 & Bom & 3 \\
\hline Manaus & 63 & Bom & 4 \\
\hline Porto Alegre & 63 & Bom & 4 \\
\hline Recife & 63 & Bom & 4 \\
\hline Aracajú & 61 & Bom & 5 \\
\hline Salvador & 56 & Médio & 6 \\
\hline Florianópolis & 52 & Médio & 7 \\
\hline
\end{tabular}


Raupp, Sacramento, Santos \& Pinho, Teoria e Prática em Administração, v. 11, edição especial em saúde

\begin{tabular}{l|l|l|l}
\hline Brasília & 44 & Médio & 8 \\
\hline Palmas & 44 & Médio & 8 \\
\hline Teresina & 41 & Médio & 9 \\
\hline Rio de Janeiro & 35 & Baixo & 10 \\
\hline Natal & 33 & Baixo & 11 \\
\hline Vitória & 33 & Baixo & 11 \\
\hline Belo Horizonte & 31 & Baixo & 12 \\
\hline Belém & 28 & Baixo & 13 \\
\hline Cuiabá & 28 & Baixo & 13 \\
\hline Fortaleza & 26 & Baixo & 14 \\
\hline Curitiba & 24 & Baixo & 15 \\
\hline Goiânia & 24 & Baixo & 15 \\
\hline Campo Grande & 22 & Baixo & 16 \\
\hline São Paulo & 20 & Baixo & 17 \\
\hline Maceió & 17 & Opaco & 18 \\
\hline Boa Vista & 13 & Opaco & 20 \\
\hline São Luís & 26 & 19 \\
\hline
\end{tabular}

Fonte: Dados da pesquisa (2021)

No total já são 17 capitais que tem utilizado o Vacinômetro para disponibilizar as informações. Ressalta-se, no entanto, que Curitiba aderiu ao Vacinômetro, mas informa apenas o número total de vacinados. As demais informações coletadas para Curitiba foram encontradas em "notícias". Rio Branco acrescentou informações sobre a vacinação no Painel Coronavírus, juntamente com informações sobre novos casos da doença, óbitos e outros. Rio Branco também disponibiliza lista de vacinados, porém, a lista não estava atualizada.

Muitos municípios não têm especificado a idade dos vacinados, mas apresentam informações gerais de faixa etária por conta de os Planos de Vacinação delimitarem as preferências por idade. Boa Vista continua fornecendo informações sobre a vacinação apenas por notícias e verificou-se que os indicadores "número de doses disponíveis", "tipo de dose" e "tipo de vacina" não foram atualizadas desde a última coleta de dados, o que fez com que a capital voltasse a apresentar nível opaco de transparência. No caso de Fortaleza, embora o Vacinômetro tenha sido atualizado em 04 de fevereiro de 2021, em "notícias" os dados estavam atualizados. Este é um exemplo de portal com notícias pulverizadas em diferentes seções, cuja característica dificulta a construção da transparência. 0 portal desta capital apresentou links de direcionamento imprecisos, por exemplo: o link "Lista de vacinados" direcionava, ao ser clicado, para "Lista de agendados para vacinação por Drive-Thru". Há também exemplos de incompletude de informações, como é o caso do portal de Maceió que apresentou informações sobre o número de vacinados de determinado público alvo em porcentagem sem especificar o quantitativo total a que esta porcentagem se refere.

0 destaque de painel de transparência sobre a vacinação neste levantamento foi para Porto Velho, cujo Vacinômetro atende a maioria dos critérios do modelo de análise, mantendo o primeiro lugar no ranking de transparência da vacinação. Mesmo demandando ainda muitos avanços, de modo geral, as capitais têm evoluído em relação à transparência. Os critérios com maior ocorrência foram: população alvo e visualização. Já os critérios menos divulgados foram: formato aberto, microdado, sexo e tipo de vacina.

\subsection{Quarto levantamento}

No quarto levantamento, realizado em 20 de fevereiro de 2021, observou-se mais uma capital aderindo ao Vacinômetro: São Luís. No total já são 18 capitais que usam essa ferramenta para disponibilizar dados sobre a vacinação em seus portais: Aracajú, Belém, Brasília, Cuiabá, Curitiba, Florianópolis, Fortaleza, João Pessoa, Macapá, Manaus, Palmas, Porto Alegre, Porto Velho, Recife, Salvador, São Luís, 
Teresina e Vitória. A Tabela 4 apresenta os dados de pontuação, nível e posição das capitais obtidos no quarto levantamento.

Tabela 4 - Pontuação, nível e posição das capitais no quarto levantamento

\begin{tabular}{|c|c|c|c|}
\hline Capital & Pontuação & Nível & Posição \\
\hline Porto Velho & 96 & Alto & 1 \\
\hline João Pessoa & 89 & Alto & 2 \\
\hline Recife & 78 & Bom & 3 \\
\hline Teresina & 74 & Bom & 4 \\
\hline Macapá & 70 & Bom & 5 \\
\hline Aracajú & 63 & Bom & 6 \\
\hline Porto Alegre & 63 & Bom & 6 \\
\hline Manaus & 59 & Médio & 7 \\
\hline Rio Branco & 56 & Médio & 8 \\
\hline Rio de Janeiro & 56 & Médio & 8 \\
\hline Salvador & 56 & Médio & 8 \\
\hline Florianópolis & 52 & Médio & 9 \\
\hline Brasília & 44 & Médio & 10 \\
\hline Palmas & 41 & Médio & 11 \\
\hline Belo Horizonte & 35 & Baixo & 12 \\
\hline Vitória & 33 & Baixo & 13 \\
\hline Natal & 31 & Baixo & 14 \\
\hline Curitiba & 30 & Baixo & 15 \\
\hline Belém & 28 & Baixo & 16 \\
\hline Fortaleza & 26 & Baixo & 17 \\
\hline São Luís & 26 & Baixo & 17 \\
\hline Boa Vista & 24 & Baixo & 18 \\
\hline Cuiabá & 24 & Baixo & 18 \\
\hline São Paulo & 24 & Baixo & 18 \\
\hline Goiânia & 22 & Baixo & 19 \\
\hline Maceió & 15 & Opaco & 20 \\
\hline Campo Grande & 13 & Opaco & 21 \\
\hline
\end{tabular}

Fonte: Dados da pesquisa (2021)

Também utilizam painéis para divulgação, entretanto sem a denominação de Vacinômetro, as seguintes capitais: Belo Horizonte, Natal, Rio Branco e Rio de Janeiro. Ainda há capitais que disponibilizam informações apenas em notícias: Boa Vista, Campo Grande, Goiânia, Maceió e São Paulo. Nota-se que estas últimas capitais mantiveram níveis de transparência baixo ou opaco em todas as coletas de dados.

A capital Campo Grande desenvolveu um portal com essa finalidade, mas traz apenas informações sobre triagem e plano de vacinação. Em notícias apresentou apenas um informe desde a coleta de dados anterior (terceiro levantamento). Esta capital regrediu do nível baixo para opaco na última análise. Embora tenha sido observado que Cuiabá utiliza o Vacinômetro desde a primeira coleta 
de dados (primeiro levantamento), a capital manteve o nível baixo de transparência em todos os levantamentos. A dinâmica da comunicação por meio do portal tem foco em previsões e notícias futuras. Quando traz notícias sobre fatos já ocorridos, foca em depoimentos de pessoas que tomaram a vacina, sem apresentar dados concretos sobre número de vacinados e outros dados relevantes para o modelo de análise.

Ressalta-se que algumas capitais têm noticiado a falta de doses e a falta de previsão do seu recebimento pelo Governo Federal. Cuiabá, Curitiba, Manaus, Rio de Janeiro e Salvador especificaram o assunto em notas de esclarecimento e notícias. No painel Covid de Curitiba há uma informação de que os dados de vacinação estão em fase de consolidação. Até o momento, Curitiba apresenta Vacinômetro apenas com o número total de vacinados, mantendo o nível de transparência baixo em todas as análises. De modo geral, notou-se uma diminuição do número de notícias nos sites das capitais relacionadas à vacinação. Os critérios com maior ocorrência foram: população alvo, tipo de dose e visualização. Já os critérios menos divulgados foram: formato aberto e sexo.

\section{Discussão}

Considera-se oportuno que aqui se recuperem alguns pontos de discussão que foram utilizados no referencial teórico a fim de proporcionar uma compreensão mais ampla do resultado final desses quatro levantamentos e o que ele pode revelar, tanto sobre o comportamento dos entes governamentais investigados bem como do papel da transparência nesse cenário da vacinação emergencial no Brasil. Uma primeira ponderação que se faz é com base em Santos e Mota (2020), quando tratam do "próprio papel da informação do setor público para o debate atual que a sociedade promove a respeito da pandemia da Covid-19" (Idem, p. 3719). Este ponto revela a importância da busca e sistematização de informações que possam sustentar discussões e análises sobre o processo de vacinação contra a Covid-19.

A própria mídia veicula as informações que são disponibilizadas pelos órgãos governamentais. Mesmo que haja uma tentativa da mídia de traduzir em uma linguagem acessível ao cidadão, a base destas informações é gerada e disponibilizada pelo setor público. Portanto, se não há organização e/ou esforços dos governos neste sentido, nem mesmo a mídia poderá informar sobre os avanços neste sentido. Esse diagnóstico reforça o exposto por Martins (2016) e Pinho (2016) quando pontuam sobre a dificuldade que persiste no Brasil para que as propostas que, a exemplo da transparência, mexem nas estruturas tradicionais, consigam prosperar. Tal questão não está restrita à mídia, pois "em momentos de isolamento social decorrentes de pandemia, os cidadãos procuram na internet informações para que possam se inteirar da real situação. As rotinas estão sendo reinventadas, e alguns encontram nas TIC apoio para manter o isolamento social" (Raupp \& Pinho, 2020, p. 3736). No que se refere à realidade empírica investigada, observa-se um ritmo diferente entre as gestões das capitais, visto que há portais muito desenvolvidos e outros, na sua maioria, nos extratos inferiores.

O segundo ponto que "também trata da importância da informação para o momento atual, concentra-se no setor mais específico das políticas públicas" (Santos \& Mota, p. 3720). Nesta mesma linha, segundo a OKBR (2020, p. 3) "a gestão e divulgação de dados é fundamental nesse esforço. No Brasil, porém, ainda temos uma heterogeneidade grande na forma de coleta e divulgação de dados, o que pode dificultar a realização de pesquisas e o monitoramento por parte dos próprios gestores e da sociedade como um todo". Esta heterogeneidade de certa forma é observada na pesquisa com as capitais brasileiras, sendo os achados relevantes às gestões para que possa observar substancialmente os critérios do modelo de análise em que a construção da transparência ainda se mostra muito aquém do patamar esperado. Pode-se inferir ainda que essa heterogeneidade decorre do não atendimento às recomendações contidas no Plano Nacional de Operacionalização da Vacinação contra a Covid-19, ou seja, aquela conclusão de Sacramento e Pinho (2016) no estudo que revelou que não é por falta de normativos que a transparência não se estabeleceu ainda como um valor social no país, também é pertinente para essa particular investigação sobre a vacinação emergencial.

Já no terceiro ponto, Santos e Mota (2020, p. 3720) afirmam "que o cenário de crise instalada tem, de certo modo, borrado a noção habitual do fluxo entre demanda e oferta na transparência governamental". Exemplificam que "o setor jornalístico passa a acompanhar mais de perto os protocolos que os governos adotam. Já as entidades de controle do Estado e da sociedade civil, certamente, se atentam para a fiscalização de recursos públicos direcionados à crise" (Idem, p. 3720). Mesmo os números das capitais se mostrando insatisfatórios em termos de transparência ativa sobre a vacinação contra a Covid-19, Pinho et al. (2020, p. 269-272) ponderam duas questões que parecem ser aplicar ao contexto da pesquisa em tela. "Primeiro, a pandemia, enquanto fato novo que demanda urgência na busca de soluções, releva a transparência das informações para um segundo momento. (...) Segundo, considerando que se trata de uma primeira aplicação do modelo de análise, este poderia ser considerado exigente", levando em consideração resultados de estudos anteriores. 
No quarto ponto "a ênfase recai sobre as demandas por informação do setor público. Isto é, elas têm sido específicas durante a pandemia e dentro de uma perspectiva de demanda cumulativa e evolutiva" (Santos \& Mota, 2020, p. 3720). Para a OKBR (2020, p. 7), "a evolução também pode servir como aliada em estudos de eficácia de tratamentos e em análises de políticas públicas". 0 modelo de análise possui um critério específico para verificar a existência ou não de uma base única e atualizada com o histórico completo, desde o início da aplicação da vacina. Todavia o critério ainda é atendido por uma minoria das capitais.

O quinto e último ponto considera "a resposta que os governos têm dado para as demandas por dados e informações no atual momento do país" (Santos \& Mota, 2020, p. 3721). De certa forma, o interesse geral do presente estudo está alinhado com este ponto, já que procura caracterizar a prática da transparência ativa das capitais brasileiras na vacinação contra a Covid-19. Quando as capitais brasileiras são analisadas em termos de pontuação geral, nível e posição no ranking, é percebida uma evolução lenta. Não foram verificadas mudanças apreciáveis, mas um estado mais estacionário, resultado este que é convergente com o pontuado por Michener, Contreras e Niskier (2018), especificamente sobre a valorização da opacidade em detrimento da transparência pela maioria dos políticos estaduais e municipais, ressalvando que nesse estudo especifico apenas o âmbito municipal foi observado. 0 que coaduna com o estudo de Raupp e Pinho (2020, p. 3736), pois afirmam que mesmo os dados revelando "uma preocupação de alguns governos em construir melhores condições de disponibilização de informações" entendem que os governos devem evoluir em transparência das informações. "Melhorá-los é importante, não apenas nesta realidade pandêmica, mas para o bom funcionamento da democracia" (Rodrigues et al., 2020, p. 134).

As capitais João Pessoa e Porto Velho merecem destaque, pois se aproximaram da pontuação máxima em todos os levantamentos. A maturidade destas capitais em gestão de TI e transformação digital pode ser mais desenvolvida em alguns aspectos do que as demais. Em termos de transparência na administração pública nos governos, Paraíba e Rondônia também se destacam no ranking nacional de transparência do Ministério Público Federal (MPF) já nos anos de 2015 e 2016. No mesmo ranking do MPF, relacionado às capitais, observa-se diversas cidades do Norte/Nordeste (inclusive Porto Velho e João Pessoa) em boas colocações. Já em um recente resultado divulgado pela Controladoria Geral da União (CGU), referente à segunda edição da Escala Brasil Transparente, das 14 capitais que obtiveram notas entre 9 e 10, nove (9) são da região Norte/Nordeste, inclusive João Pessoa e Porto Velho. Portanto, não é surpresa que essas capitais apareçam com bons níveis de transparência sobre a vacinação, pois elas já vêm demonstrando um histórico de transparência na avaliação de órgãos de controle.

Do exposto, pode-se afirmar que o extrato com maior ocorrência nos levantamentos efetuados foram capitais com baixo nível de transparência ativa no que tange à campanha de vacinação contra a Covid-19, tendo o processo de accountability dificuldades para ser efetivado no Brasil. Como lecionado por Schedler (1999), a deficiência dos elementos da informação e justificação, básicos da dimensão answerability, afetam a capacidade de enforcement, ou seja, a outra dimensão do modelo que contempla o poder de agências para a aplicação de sanções e até perda de mandato ou função àqueles que transgridam os deveres públicos.

\section{Conclusões, Contribuições e Limitações do Estudo}

O objetivo central dessa investigação foi o de caracterizar a prática da transparência ativa das capitais brasileiras na vacinação contra a Covid-19, a partir de uma adaptação do Índice de Transparência da Covid-19 (ITC-19) elaborado pela Open Knowledge Brasil (OKBR). As capitais brasileiras, na sua maioria, ainda não utilizam todo o potencial dos portais eletrônicos para avançar na construção da transparência ativa sobre a vacinação contra a Covid-19. Ainda que boas práticas tenham sido identificadas, há questões que podem e devem ser aperfeiçoadas. A boa prática de destaque fica por conta da utilização do Vacinômetro por algumas capitais enquanto painel que reúne a maioria das informações sobre o processo de vacinação. Isto não significa dizer que todas as capitais que disponibilizam um painel com esta denominação o fazem como boa prática, já que algumas o mantém com um mínimo de informações. Os principais pontos passíveis de melhora ficam por conta do baixo atendimento dos critérios por algumas capitais; informações desatualizadas; informações fragmentas em diferentes seções do portal; e ausência de padronização na forma de veiculação da informação que pode ser por meio de notícias, informes, boletins epidemiológicos e/ou painéis.

O Brasil é tido como um país que tem tradição e experiência em vacinação em massa. Além disso, a sociedade brasileira tem girado neste último ano em torno da questão da Covid-19, assim, as estruturas governamentais não podem dizer que foram pegas de surpresa. Tem sido apontado pelos especialistas que estamos aprendendo a lidar com a pandemia do ponto de vista da saúde pública, o que constitui um desafio pelo caráter inédito deste fenômeno, considerando que a última se deu 100 
anos atrás em um país e um mundo diferente do atual. No que toca à transparência, ou seja, do ponto de vista da democracia, já se tem pelo menos duas décadas da discussão e consideração deste valor e os resultados ainda são insuficientes. Poder-se-ia dizer que também a transparência tem uma "história lenta".

Os próprios entes passaram os últimos meses adaptando os seus portais para que pudessem disponibilizar informações sobre a Covid-19, desde questões epidemiológicas até contratações emergências (BRASIL, 2020), o que pressupunha que uma adaptação para informações sobre a vacinação tivesse ocorrido e/ou sido mais efetiva. Então, o que parece que nos falta mesmo é a transparência como um valor consolidado na realidade brasileira, e que pode ser explicado em parte por questões mais estruturais do contexto brasileiro, conforme apresentado nos fundamentos teóricos. De qualquer forma, dá para perceber que já existe algum esforço de busca e engajamento por muitos governos de capitais para realizar este valor tão próprio da democracia, visto a evolução de algumas capitais em termos de pontuação geral, nível e posição no ranking.

0 estudo contribui em termos acadêmicos e práticos. Para a academia, particularmente à área de conhecimento que se debruçou, reside no fato de se ter desenvolvido uma pesquisa sobre transparência no processo de vacinação, considerada inédita no âmbito nacional, já que uma busca na base Spell não retornou artigos desta natureza. Como não foram identificadas pesquisas anteriores, o estudo teve o mérito de principiar o preenchimento dessa lacuna. Na questão prática, a contribuição de destaque consistiu no desenvolvimento de um modelo específico para avaliar a transparência na vacinação, o Índice de Transparência da Vacinação contra a Covid-19 no Brasil, instrumento que possui relevância social. 0 mínimo que se espera é que o cidadão possa acompanhar o andamento e resultados do processo de vacinação. Da mesma forma, os resultados servem de alerta às gestões das capitais, principalmente em relação àqueles critérios cuja construção da transparência pode e deve ser aperfeiçoada.

Uma das limitações deste estudo refere-se ao fato de não se levar em conta as discrepâncias socioeconômica e financeira existentes entre os entes pesquisados, pois se sabe que a transparência também demanda recursos dessas ordens para a sua promoção. Outra limitação relaciona-se às rápidas mudanças da tecnologia, neste caso os portais, em que aperfeiçoamentos ou mesmo retrocessos poderão contribuir para realidades empíricas diferentes em um curto espaço de tempo. Não obstante, reconhece-se que o estudo proveu subsídios interessantes, que apontam sugestões para a possibilidade da realização de futuros estudos comparativos, ou ainda de pesquisas mais aprofundadas, inclusive fazendo uso de métodos quantitativos que sinalizem quais varáveis poderiam explicar os diferentes níveis de transparência dessas capitais, tema que, no nosso entendimento, é de relevância social.

\section{Referências}

Campos, A. M. (1990). Accountability: quando poderemos traduzi-la para o português? Revista de Administração Pública, 24(2), 30-50.

Carvalho, J. M. de. (2014). Cidadania no Brasil: o longo caminho. Rio de Janeiro: Civilização Brasileira.

Lei Complementar n. 131, de 27 de maio de 2009. (2009). Acrescenta dispositivos à Lei Complementar no 101 , de 4 de maio de 2000, que estabelece normas de finanças públicas voltadas para a responsabilidade na gestão fiscal e dá outras providências, a fim de determinar a disponibilização, em tempo real, de informações pormenorizadas sobre a execução orçamentária e financeira da União, dos Estados, do Distrito Federal e dos Municípios. Recuperado de http://www.planalto.gov.br/ ccivil_03/leis/lcp/lcp131.htm

Lei Complementar n. 135, de 04 de junho de 2010. (2010). Altera a Lei Complementar no 64, de 18 de maio de 1990, que estabelece, de acordo com o § 9o do art. 14 da Constituição Federal, casos de inelegibilidade, prazos de cessação e determina outras providências, para incluir hipóteses de inelegibilidade que visam a proteger a probidade administrativa e a moralidade no exercício do mandato. Recuperado de http://www.planalto.gov.br/ccivil_03/leis/lcp/lcp135.htm

Lei Complementar n. 101, de 04 de maio de 2000. (2000). Estabelece normas de finanças públicas voltadas para a responsabilidade na gestão fiscal e dá outras providências. Recuperado de http:// www.planalto.gov.br/ccivil_03/leis/lcp/lcp101.htm

Lei n. 13.979, de 06 de fevereiro de 2020. (2020). Dispõe sobre as medidas para enfrentamento da emergência de saúde pública de importância internacional decorrente do coronavírus responsável pelo surto de 2019. Recuperado de: http://www.planalto.gov.br/ccivil_03/_ato2019-2022/2020/lei/ L13979.htm.

Martins, J. de S. (2011). A política do Brasil: lúmpen e místico. São Paulo: Contexto.

Martins, J. de S. (2016). Do PT das lutas sociais ao PT do poder. São Paulo: Contexto.

Michener, G., Contreras, E., \& Niskier, I. (2018). Da opacidade à transparência? avaliando a Lei de 
Acesso à Informação no Brasil cinco anos depois. Revista de Administração Pública, 52(4), 610-629.

Motta, P. R. M. (2013). 0 estado da arte da Gestão Pública. Revista de Administração de Empresas, 53(1), 82-90.

Open Knowledge Brasil (2020). Índice de Transparência da Covid-19: nota metodológica. Recuperado d e ht t s : / / transparencia covid 19 . ok .org.br/files / Nota_Metodologica_Transparencia_da_Covid-19_2.0.pdf

Pinho, J. A. G. de. (2016). Reforma da administração pública no Brasil: a resistência do "bunker" patrimonialista e a reforma que não acontece. Sociedade, Contabilidade e Gestão, 11(3), 130-140.

Pinho, J. A. G. de, \& Sacramento, A. R. S. (2009). Accountability: já podemos traduzi-la para o português? Revista de Administração Pública, 43(6), 1343-1368.

Pinho, J. A. G. de, Sacramento, A. R. S., Raupp, F. M., \& Amaral, M. S. (2020). Transparência governamental em capitais dos estados no Brasil nas contratações emergenciais para o combate da Covid-19. Revista da CGU, 12(22), 260-274.

Plano Nacional de Operacionalização da Vacinação contra a Covid-19. (2020). Recuperado de https:// www.gov.br/saude/pt-br/media/pdf/2020/dezembro/16/plano_vacinacao_versao_eletronica-1.pdf

Ramos, A. G. (1983). Administração e contexto brasileiro: esboço de uma teoria geral da administração. Rio de Janeiro: FGV.

Raupp, F. M.; Pinho, J. A. G. de. (2020). Precisamos evoluir em transparência? - uma análise dos estados brasileiros na divulgação de informações sobre a Covid-19. Gestão e Sociedade, 14(39), 3725-3739.

Rodrigues, R. V., Silva, L. F., Boechat, G., Coli, H., Carvalho, D. C. B. (2020). Transparency on Covid-19 pandemic: an evaluation of brazilian municipalities. Revista do Serviço Público, 71(Edição Especial A), 111-139.

Santos, J. G. D., \& Mota, F. P. B. (2020). A transparência governamental em tempos de Covid-19: reflexões do quadro brasileiro. Gestão e Sociedade, 14(39), 3716-3724.

Sacramento, A. R. S., \& Pinho, J. A. G. (2016). The process of implementing answerability in contemporary Brazil. Revista de Administração Pública, 50(2), 193-213.

Schedler, A. (1999). Conceptualizing accountability. In: Schedler, A., Diamond, L., \& Plattner M. F. (Eds). The self-restraing state: power and accountability in new democracies (pp. 13-28). Boulder and London: Lynne Rienner Publishers.

Vieira, K. M., Pegoraro, D., Visentini, M. S. (2020). Percepção de Transparência Ativa e Passiva nas Instituições de Ensino: Proposição e Validação de um Questionário. Revista de Educação e Pesquisa em Contabilidade, 14(1), 34-55.

Zuccolotto, R., Teixeira, M. A. C. (2019). Transparência: aspectos conceituais e avanços no contexo brasileiro. Brasília: Enap. 